\title{
Effect of Plant Growth Regulators on Flowering Parameters of Ber (Zizyphus mauritiana Lamk)
}

\author{
Kishore Kumar Das*, P. K. Yadav, S. R. Bhunia and R. S. Singh \\ Swami Keshwan and Rajasthan Agricultural University, Bikaner, Rajasthan, India \\ *Corresponding author
}

Keywords

NAA, GA, BAP, fruit retention, fruit drop

\section{Article Info}

Accepted:

20 February 2020

Available Online:

10 March 2020

\section{A B S T R A C T}

The study was conducted at Niche Area of Excellence Farm, SKRAU, Bikaner (Rajasthan), during the year 2017-18 and 2018-19. Foliar application of plant growth regulators viz. NAA (0, 20 \& 40 ppm), GA3 (0, $20 \& 40 \mathrm{ppm})$, BAP $(0,10,20 \mathrm{ppm})$ were applied 6 years old ber trees. The results revealed that treatment NAA $20 \mathrm{ppm}$ significantly minimize the days taken for initiation of flowering, days taken for $50 \%$ blooming and days taken for full bloom, and harvesting. NAA $20 \mathrm{ppm}$ increased fruit set, fruit retention, least fruit drop, in both the years as well as in polled analysis as compare to control. Similarly, application of GA3 20 ppm increased fruit set, fruit retention and least fruit drop, during both the years and pooled mean as compared to control.

\section{Introduction}

Ber (Zizyphus mauritiana Lamk), the poor man's fruit is one of the most ancient and common indigenous fruit in India and belonging to family Rhamnaceae. According to De Candolle (1886), the centre of origin for this fruit crop is central Asia and it is found growing wild as well as in cultivated forms throughout the warmer regions up to an altitude of 1500 meters above mean sea level. It can be successfully grown even in the most marginal ecosystems of the sub-tropics and tropics (Pareek, 2001). Ber is popular due to its high economic returns, low cost of cultivation wider adaptability and ability to withstand drought (Gupta, 1983). The Indian jujube is native of Province of Yunnan in southern China to Afghanistan, Malaysia and Queensland, Australia. Ber has been in use for almost 4000 years in India.

It is cultivated to some extent throughout its natural range but mostly in India where it is grown commercially and has received much horticultural attention and refinement despite the fact that it frequently escapes pests. Specimens are scattered about the drier parts 
of the West Indies, the Bahamas, Colombia, Venezuela, Guatemala, Belize, and southern Florida. In Barbados, Jamaica and Puerto Rico the tree is naturalized and forms thickets in uncultivated areas. Zizyphus sp. found growing wild, semi wild and also cultivated in almost all parts of India. The major growing states are Madhya Pradesh, Bihar, Uttar Pradesh, Punjab, Haryana, Rajasthan, Gujarat, Maharashtra and Andhra Pradesh. Ber occupied an area of 858 thousand hectare with an annual production of 481 thousand MT per year in India (NHB, 2017).

Plant growth regulators play a significant role in many physiological phenomena. Those are being used in vegetative propagation, regulation of flowering, thinning of flower and fruit, artificial induction of seedlessness, improvement of fruit set and size and prevention of pre-harvest fruit drop. Plant growth regulators also play major role in the development of fruits (Singh et al., 1990).

They act as metabolic sink for the diversion of metabolic from one part to other of the plant specially towards developing fruits. The pre harvest sprays of PGRs being used to control fruit drop and to improve fruit retention percentage. Among various plant growth regulators, NAA is an important growth regulator of auxin group, which helps to reduce fruit drop and to improve fruit set and quality specially TSS.

Gibberellic acid is an important growth regulator of gibberellins group and used to improve fruit size and quality viz. to increase the juice percentage and TSS. $\mathrm{GA}_{3}$ also found use in increasing sugar content, inducing flowering, delaying in maturity and producing seedlessness. The effects of synthetic cytokinins are consistent with the functions of the endogenous compounds. Following application, enhanced chloroplast differentiation and chlorophyll synthesis result in delayed senescence. Cytokinins have been implicated in apical dominance. The synthetic cytokinins usually stimulate flower induction.

\section{Materials and Methods}

The study entitled "Effect of Foliar Spray of Plant Growth Regulators on Flowering, Fruit drop, Yield and Quality of Ber (Zizyphus mauritiana Lamk) in Arid Conditions" was conducted at Niche Area of Excellence Farm, SKRAU, Bikaner (Rajasthan), during the year 2017-18 and 2018-19.The experiment was laid out in Randomized Block Design having 27 treatments with three replications each. Foliar application of plant growth regulators viz. NAA $(0,20 \& 40 \mathrm{ppm}), \mathrm{GA}_{3}(0,20 \& 40$ ppm), BAP $(0,10,20 \mathrm{ppm})$ were applied 6 years old ber trees. The plants cv. Gola selected for study and a uniform cultural schedule was followed in all the treatments during the course of investigation.

\section{Results and Discussion}

The perusal of data in table 4.1 revealed that application of NAA resulted into a significant difference between the treatments in both years (2017-18, 2018-19 and pooled mean). The minimum days taken for initiation of flowering (6.41 days), days taken to $50 \%$ blooming and full blooming was found in the plants receiving treatment NAA $40 \mathrm{ppm}$ which was at par with treatment NAA 20 ppm, while delayed initiation of flowering, days taken to $50 \%$ blooming and full blooming was observed in control (NAA 0 ppm) in both year and pooled mean.

Flowering of ber was associated with reduced vegetative growth and available evidence strongly suggest that flower initiation depends on the presence of an unknown flower promoting factor or factors synthesised in the leaves. As NAA was found to have flowering 
promoting activity (Oksher et al., 1980). The observed reduction in vegetative growth in present investigation may be due to inhibitory effect of flower promoting factors on vegetative growth in plants; because of NAA is a flowering hormone. Flower bud initiation and flowering are guided by different plant hormones and the nutrient status of the plant. Early flowering would refer to an early morphological differentiation. Flowering is mediated by increased levels of endogenous auxinthat may simply hasten flower emergence of a differentiated dormant bud. The earliness in blooming of flower bud due to NAA treatment might be associated with its action in promoting the flow of metabolites towards flowering buds and thus fasten the floral development (Krishna et al., 2017). Similar results were observed by Lal et al., (2013) in guava. It is evident from the table (4.2) that fruit set and fruit retention was significantly influenced by spray of NAA.

Foliar spray of NAA at 40 ppm significantly increased the fruit set $(92.31,91.31$, and 91.81 percent) and retention $(61.13,59.43$, 60.28) of ber over control in both the years (2017-18 and 2018-19) and pooled basis respectively. However, NAA $40 \mathrm{ppm}$ and NAA 20 ppm levels were at par in respect of fruit set and fruit retention. However, NAA $40 \mathrm{ppm}$ and NAA $20 \mathrm{ppm}$ increased fruit set by $(8.33,10.06,9.18$ percent and $6.9,9.25$, 8.06 percent) and fruit retention $(20.98,24.63$ and 22.75 percent and 20.45, 23.01 and 21.70) as compared to control, respectively.

Data (Table 4.2 further revealed that application of $\mathrm{GA}_{3}$ significantly increased the fruit set and fruit retention percentage of ber over control during the year 2017-18, 2018-19 and pooled mean. Among the levels of $\mathrm{GA}_{3}$ $40 \mathrm{ppm}$ recorded maximum fruit set (92.64, 91.72, and 92.18 per cent) and fruit retention $\left(61.06,59.91\right.$, and 60.48) followed by $\mathrm{GA}_{3} 20$ ppm. The least fruit set and fruit retention percentage were observed in control $\left(\mathrm{GA}_{3} \mathrm{O}\right.$ ppm). The effect of Treatment NAA accelerates the metabolic activities of the plant by increasing the meristematic activities which in turn increases the vegetative growth, more photosynthesis and ultimately lead to increase flowering, maximum fruit setting and maximum fruit retention per cent. Similar results have also been reported by Zang and Lei (2000) and Shankar et al., (2002) in guava.

The dropping of fruit might be due to low auxin activity or limited auxin like precursor for developing fruits as reported in navel orange (Lima and Davies, 1984). Reduction in fruit drop in this experiment by the application of growth regulators may be attributed by correcting the deficiency of endogenous auxin which prevents the formation of abscission layer possibly through the inhibition of enzymatic activity such as pectinase, cellulose and also polygalactauronase (Singh and Singh, 1976) in ber.

The higher fruit set in response to higher concentration of growth substances like $\mathrm{GA}_{3}$ application is probably due to translocation of hormones, food substances and other factors stimulating fruit formation to the tissue of ovary in greater amount. It is clear from the data (Table 4.2) that application of NAA brought about significant variation in fruit drop of ber during both the years (2017-18 and 2018-19) and pooled mean.

The least fruit drop percentage was observed in NAA 40 ppm $(31.26,31.86$, and 31.55) followed by NAA $20 \mathrm{ppm}(31.91,32.13$, 32.02). The maximum fruit drop was observed in NAA 0 ppm. Further revealed that application of $\mathrm{GA}_{3} 40 \mathrm{ppm}$ was recorded minimum fruit drop $(32.07,32.10,32.09$ percentage) which was at par with $\mathrm{GA}_{3} 20$ ppm (32.28, 32.59, 32.43 percentage) during both years and pooled basis. 
Table.1 Effect of foliar application of NAA, GA 3 and BAP on flowering of ber

\begin{tabular}{|c|c|c|c|c|c|c|c|c|c|}
\hline \multirow[t]{2}{*}{ Treatments } & \multicolumn{3}{|c|}{ Initiation of flowering } & \multicolumn{3}{|c|}{ Days taken for $50 \%$ blooming } & \multicolumn{3}{|c|}{ Days taken for full bloom } \\
\hline & $2017-18$ & $2018-19$ & Pooled & $2017-18$ & $2018-19$ & Pooled & $2017-18$ & 2018-19 & Pooled \\
\hline \multicolumn{10}{|c|}{ Levels of NAA (ppm) } \\
\hline $\mathbf{N A A _ { 0 }}$ & 8.33 & 6.93 & 7.63 & 16.81 & 16.93 & 16.87 & 36.85 & 35.67 & 36.26 \\
\hline $\mathbf{N A A}_{20}$ & 6.50 & 5.36 & 5.93 & 15.59 & 15.67 & 15.63 & 35.37 & 33.61 & 34.49 \\
\hline $\mathbf{N A A}_{40}$ & 6.41 & 5.17 & 5.79 & 15.26 & 15.40 & 15.33 & 35.07 & 33.26 & 34.17 \\
\hline SEm \pm & 0.141 & 0.137 & 0.098 & 0.158 & 0.209 & 0.131 & 0.294 & 0.287 & 0.205 \\
\hline C.D. $(P=0.05)$ & 0.399 & 0.390 & 0.276 & 0.450 & 0.594 & 0.368 & 0.833 & 0.813 & 0.575 \\
\hline \multicolumn{10}{|c|}{ Levels of $\mathrm{GA}_{3}$ (ppm) } \\
\hline $\mathbf{G A}_{\mathbf{0}}$ & 7.01 & 5.99 & 6.50 & 16.11 & 15.97 & 16.04 & 35.74 & 34.12 & 34.93 \\
\hline $\mathbf{G A}_{20}$ & 7.14 & 5.88 & 6.51 & 15.89 & 16.27 & 16.08 & 35.93 & 33.86 & 34.89 \\
\hline $\mathbf{G A}_{40}$ & 7.10 & 5.58 & 6.34 & 15.67 & 15.75 & 15.71 & 35.63 & 34.56 & 35.10 \\
\hline SEm \pm & 0.141 & 0.137 & 0.098 & 0.158 & 0.209 & 0.131 & 0.294 & 0.287 & 0.205 \\
\hline C.D. $(P=0.05)$ & N.S & N.S & N.S & N.S & N.S & N.S & N.S & N.S & N.S \\
\hline \multicolumn{10}{|c|}{ Levels of BAP (ppm) } \\
\hline $\mathbf{B A P}_{0}$ & 7.19 & 5.69 & 6.44 & 15.85 & 16.08 & 15.97 & 35.85 & 34.60 & 35.23 \\
\hline $\mathbf{B A P}_{10}$ & 7.05 & 5.99 & 6.52 & 16.04 & 15.93 & 15.99 & 36.07 & 34.08 & 35.08 \\
\hline $\mathbf{B A P}_{20}$ & 7.01 & 5.77 & 6.39 & 15.78 & 15.97 & 15.87 & 35.37 & 33.86 & 34.61 \\
\hline SEm \pm & 0.141 & 0.137 & 0.098 & 0.158 & 0.209 & 0.131 & 0.294 & 0.287 & 0.205 \\
\hline C.D. $(P=0.05)$ & N.S & N.S & N.S & N.S & N.S & N.S & N.S & N.S & N.S \\
\hline
\end{tabular}

N.S- Non Significant 
Table.2 Effect of foliar application of NAA, $\mathrm{GA}_{3}$ and BAP on fruit set, fruit drop and fruit retention of ber

\begin{tabular}{|c|c|c|c|c|c|c|c|c|c|}
\hline \multirow[t]{2}{*}{ Treatments } & \multicolumn{3}{|c|}{ Fruit set $(\%)$} & \multicolumn{3}{|c|}{ Fruit drop (\%) } & \multicolumn{3}{|c|}{ Fruit retention (\%) } \\
\hline & $2017-18$ & 2018-19 & Pooled & 2017-18 & 2018-19 & Pooled & $2017-18$ & 2018-19 & Pooled \\
\hline \multicolumn{10}{|c|}{ Levels of NAA (ppm) } \\
\hline $\mathbf{N A A}_{0}$ & 85.21 & 82.96 & 84.09 & 34.55 & 34.74 & 34.64 & 50.75 & 48.31 & 49.53 \\
\hline $\mathbf{N A A}_{20}$ & 91.10 & 90.64 & 90.87 & 31.91 & 32.13 & 32.02 & 61.13 & 59.43 & 60.28 \\
\hline $\mathbf{N A A}_{40}$ & 92.31 & 91.31 & 91.81 & 31.26 & 31.86 & 31.56 & 61.40 & 60.21 & 60.80 \\
\hline SEm \pm & 0.282 & 0.546 & 0.307 & 0.292 & 0.309 & 0.213 & 0.417 & 0.261 & 0.417 \\
\hline C.D. $P=0.05$ ) & 0.800 & 1.549 & 0.862 & 0.830 & 0.877 & 0.596 & 1.184 & 0.732 & 1.184 \\
\hline \multicolumn{10}{|c|}{ Levels of $\mathbf{G A}_{3}(\mathrm{ppm})$} \\
\hline $\mathbf{G A}_{0}$ & 83.85 & 81.58 & 82.71 & 33.36 & 34.03 & 33.69 & 51.39 & 48.58 & 49.98 \\
\hline $\mathbf{G A}_{20}$ & 92.15 & 91.62 & 91.88 & 32.28 & 32.59 & 32.43 & 60.82 & 59.47 & 60.15 \\
\hline $\mathbf{G A}_{40}$ & 92.64 & 91.72 & 92.18 & 32.07 & 32.10 & 32.09 & 61.06 & 59.91 & 60.48 \\
\hline SEm \pm & 0.282 & 0.546 & 0.307 & 0.292 & 0.309 & 0.213 & 0.314 & 0.417 & 0.261 \\
\hline C.D. $P=0.05$ ) & 0.800 & 1.549 & 0.862 & 0.830 & 0.877 & 0.596 & 0.892 & 1.184 & 0.732 \\
\hline \multicolumn{10}{|c|}{ Levels of BAP (ppm) } \\
\hline $\mathbf{B A P}_{\mathbf{0}}$ & 89.44 & 87.92 & 88.68 & 33.22 & 33.57 & 33.40 & 56.13 & 54.65 & 55.39 \\
\hline $\mathbf{B A P}_{10}$ & 89.56 & 88.27 & 88.92 & 32.28 & 32.89 & 32.59 & 58.43 & 56.61 & 57.52 \\
\hline $\mathbf{B A P}_{20}$ & 89.63 & 88.73 & 89.18 & 32.21 & 32.26 & 32.23 & 58.71 & 56.68 & 57.70 \\
\hline SEm \pm & 0.282 & 0.546 & 0.307 & 0.292 & 0.309 & 0.213 & 0.314 & 0.417 & 0.261 \\
\hline C.D. $P=0.05$ ) & N.S & N.S & N.S & 0.830 & 0.877 & 0.596 & 0.892 & 1.184 & 0.732 \\
\hline
\end{tabular}

N.S- Non Significant 
The maximum fruit drop was observed in control (33.36, 34.03, and 33.69 percent). The percent fruit drop was reduced by the application of $\mathrm{GA}_{3} 40$ and $20 \mathrm{ppm}$ and it was 3.86, 5.67, 4.74 and 3.23, 4.23, 3.73 percent as compared to control, respectively. Application of BAP also significantly minimizes the fruit drop percentage of ber.

The treatment BAP $20 \mathrm{ppm}$ was recorded minimum fruit drop percentage $(32.21,32.26$, 32.23) and maximum fruit drop percentage was recorded in control BAP 0 ppm (33.22, $33.57,33.40)$. It also showed that BAP 20 ppm was statistically at par with the treatment BAP 10 ppm (32.28, 32.89, and 32.59). However, BAP $20 \mathrm{ppm}$ and $10 \mathrm{ppm}$ reduced fruit drop by $3.04,3.90,3.50$ percent and $2.82,2.02,2.41$ percent as compared to control, respectively.

The dropping of fruit might be due to low auxin activity or limited auxin like precursor for developing fruits as reported in navel orange (Lima and Davies, 1984). Reduction in fruit drop in this experiment by the application of growth regulators may be attributed by correcting the deficiency of endogenous auxin which prevents the formation of abscission layer possibly through the inhibition of enzymatic activity such as pectinase, cellulose and also polygalactauronase (Singh and Singh, 1976) in ber.

The primitive effect of growth substances in greater retention of fruit may be attributed to reduction in fruit drop. There is correlation between fruit drop and endogenous hormonal status, and existence of high level of internal auxin that prevent fruit drop. This action of $\mathrm{GA}_{3}$ might have raised auxin level leading to diminished drop rate and attributed to its reduction in fruit drop which prevents the formation of abscission layer as reported by Addicot (1970) in apple. Since high level of endogenous hormone at appropriate level, potent to enough reduce the fruit drop.

It is concluded that application of NAA 20 ppm, GA 20 ppm and BAP 10 ppm increases fruit set and fruit retention and reduce fruit drop as compared to rest of treatments.

\section{References}

Addicot, F.T. 1970. Plant harmone in control of abscission. Biol. Rev., 45: 485-524.

Gupta, A.K., H.S. Panwar, and B.B. Vashishtha. 1983. Studies on physicochemical changes in ber (Ziziphus mauritiana Lamk). Indian J. Hortic., 41:52-57

Krishna, G. V., Bhagwan, A. M., Kumar, R. and Shankar, A. S. 2017. Effect of flower enhancing plant growth regulators and fruit set improving chemicals on vegetative growth, early flower initiation and fruit yield of mango (Mangifera indica L.) cv. Banganpalli. Int. J. Pure App. Biosci., 5 (3): 667-677

Lal, N., Das, R.P. And Verma, L. R. 2013. Effect of plant growth regulators on flowering and fruit growth of guava (Psidium guajava L.) cv. Allahabad Safeda. The Asian Journal of Horticulture., 8(1): 54-56.

Lima, J.E.O. and Davies, F.S. 1984. Growth regulators, fruit drop, yield and quality of Navel orange in Florida. J. Amer. Soc. Hort. Sci., 109(1): 81-84.

NHB, 2017. Ministery of Agriculture and Farmers Welfaire, Government of India. http://www.nhb.gov.in

Oksher, A.K., Ramachandran, C. and Pyhodath, J.S. 1980. Effect of planofix on fruit set in mango. Agric. Res. J. Kereale, 17(1): 105

Pareek, O.P. 1983. The Ber: Indian Council of Agricultural Research, New Delhi.

Pareek, O.P. 2001. Ber: International Centre 
for Underutilized crops,

Shankar, U., Pathak, R.A., Pathak, R.K. and Ojha, C.M. 2002. Effects of NPK on the yield and fruit quality of guava cv. Sardar. Prog. Hort., 34 (1): 49-55.

Singh, U.R., and Singh, N. 1976. Effect of plant growth regulators on fruit drop, size and quality of ber (Z. mauritiana Lamk) cv. Banarsi. Haryana J. Hort., 5 (1-2): 1-8.

Zang, X. P. and Lei,X. T. 2000. The application of fertilizer for guava trees. South China Fruits., 29(6): 29-31.

\section{How to cite this article:}

Kishore Kumar Das, P. K. Yadav, S. R. Bhunia and Singh. R. S. 2020. Effect of Plant Growth Regulators on Flowering Parameters of Ber (Zizyphus Mauritiana Lamk). Int.J.Curr.Microbiol.App.Sci. 9(03): 2684-2690. doi: https://doi.org/10.20546/ijcmas.2020.903.306 